\title{
THE MULTIPLE PUNCTURE CUTANEOUS TUBERCULIN TEST
}

BY

\author{
W. S. CRAIG, B.Sc., M.B., Ch.B.,
}

Late House-phụsician, Roval Hospital for Sick Children, Edinburgh.

At a recent meeting of the National Association for the Prerention of Tuberculosis, a special plea was put forward for a wholesale examination of children of school age, with a view to discovering signs of existing latent tuberculous infection. There was general agreement that in such a routine examination the tuberculin test must play an important part, and it is the purpose of this paper to describe a technique for cutaneous tuberculin tests which, in virtue of its speedy application without sacrifice of reliability, appears particularly suited to the requirements of such extensire inrestigations.

In 1916, a tuberculin skin sensitization test known as the tattoo method was described ${ }^{1}$, ', which consisted in making a series of small punctures with a sterilized sewing needle through a film of pure old tuberculin placed on the previously cleansed skin. The tuberculin was afterwards wiped off and the test read in $\mathbf{4 8}$ hours. There was a distinct appeal in the rapidity of the above tattoo method, but the repetition of skin punctures appeared to inrolre an unnecessary amount of physical discomfort and mental strain on the patient's part. With a view to avoiding these disadrantages while still adhering to the fundamentals of the technique, we used an ordinary three-pronged raccinator, applying it twice, and exactly in the way described for the needle in the above method. In all, 50 cases were subjected to the tuberculin cutaneous test: (a) using the vaccinator, and (b) using the modified Pirquet test as described by McNeils.

The results of the two methods corresponded exactly, suggesting that the use of the vaccinator involved no loss of reliability.

At best, the use of the vaccinator was but an extempore effort, and it was felt desirable to aim at a method which by one application would affect the necessary number of skin punctures, and at the same time involve a test area constant in form and dimensions. Accordingly the instrument and technique described below were devised, and the method carried out over a series of 612 cases.

Technique of method.-The instrument (Fig. 1) consists of a handle (A), five needles (B), and a protective cap (C). The needles are so arranged that when the long axis of the instrument is held at an angle of $30^{\circ}$ to the plane of the skin, the points of the two longest $\left(a\right.$ and $\left.a^{1}\right)$ and of the two shortest ( $b$ and $b^{1}$ ) form the corners of a square on the skin plane, the point of needle (c) representing the exact centre of that square.

The method of use consists of the following steps : First, a small area of skin, preferably on the flexor aspect of the arm, is cleansed with methylated 
ether. Then with the flat tapered end of the handle, a drop of old tuberculin is transferred from the bottle to the cleansed surface.

With the instrument held as in Fig. 2, the handle at an angle of $30^{\circ}$ to the skin surface and the needle points resting on the portion of skin corered with tuberculin, pressure is applied at right angles to the plane of the test area. As pressure, which should be firm and deliberate, is applied, the points of the needles (all five at the same time) are felt to penetrate the superficial layers of the skin.

Again in a direction at right angles to the skin surface, the needle points are withdrawn, this time with a quick rapid motion, in doing which a distinct catch is felt as the superficial skin layers are passed through.

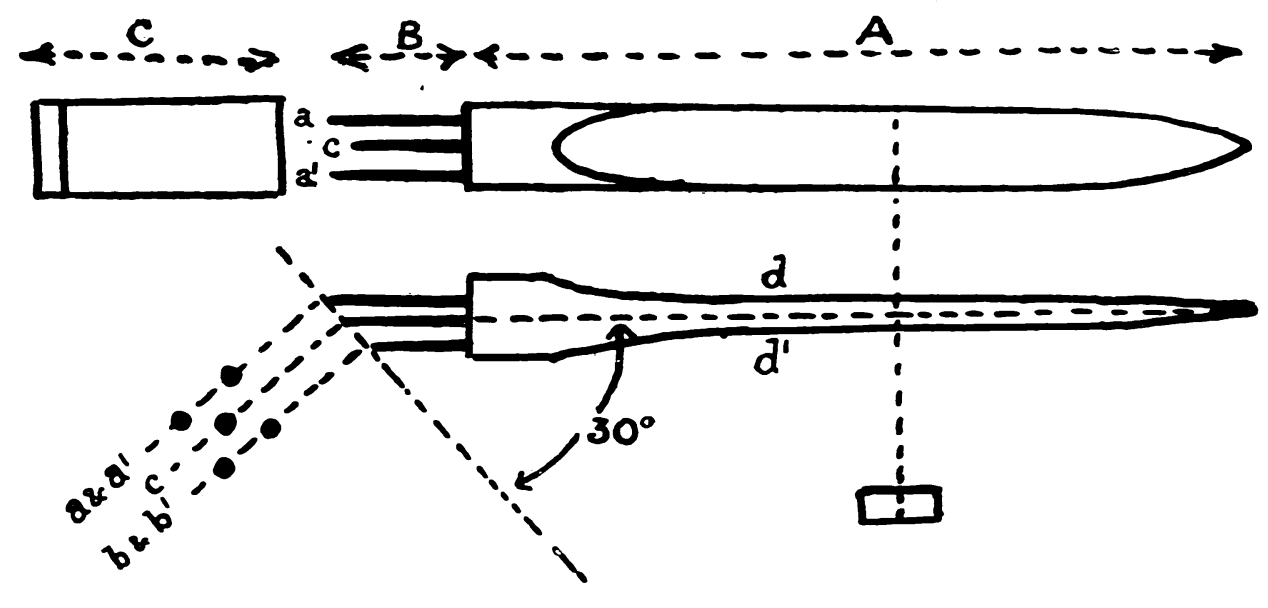

Fig. 1. Cutaneous tuberculin test instrument used in multiple puncture method. (Actual size).

It requires but one successful performance of the test to appreciate the sensation of adequate penetration and the catch on withdrawal, and these are of importance as affording very reliable indications as to whether the necessary amount of pressure has been applied. Blood is not drawn.

Finally, the excess of old tuberculin is wiped off.

Reactions are read daily for seren dars.

The nature of the reactions.-Positive reactions of various types were found to occur differing in (a) form, (b) colour, and (c) size.

(a) If examined early enough the reaction was seen to take the form of fire small red papules which, in the matter of hours, fused to give one large 
raised circular nodule. In many instances this was the maximum reaction. In other cases the nodule became both more raised and extended, alwars preserving its symmetrical shape, while in the more riolent reaction there appeared also a peripheral zone of erythema. Four cases occurred in which the erythematous zone showed continuity with a mild ascending lymphangitis.

What was taken to be the most serere reaction was found in six children. Twenty-four hours after showing an enlarged red nodule, a small white resicle arose at each puncture point and proceeded to extend in area until the fire resicles became contiguous without actually coalescing. At this stage. around the vesicular cluster the margin of the original nodule remained as a rivid

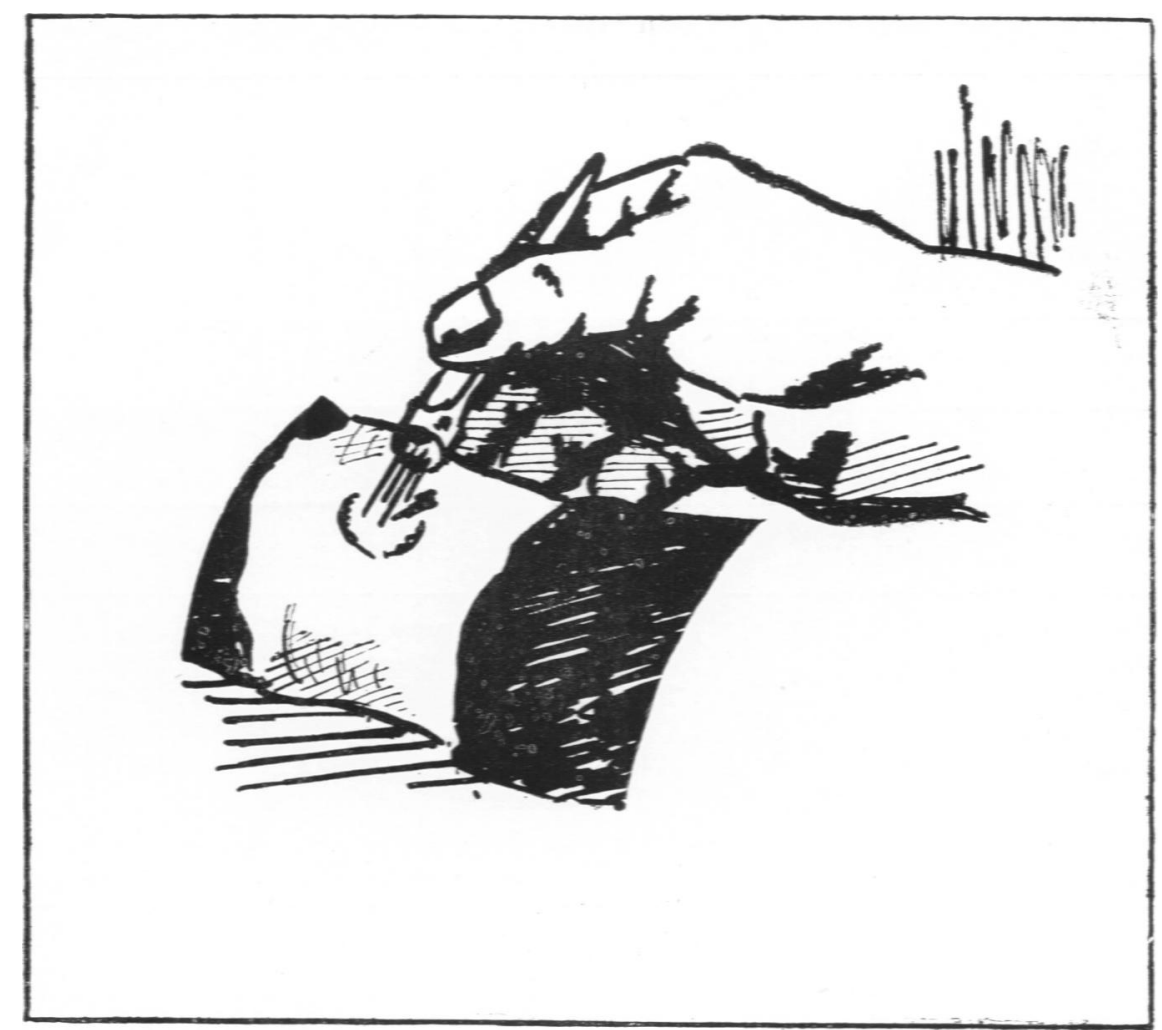

FIf. 2. Cutaneous tuberculin test : multiple puncture method.

boundary line, while outside it again there was a very broad erythematous area.

The weakest type of reaction was met with in two cases of generalized tuberculosis and one of tuberculous meningitis, the tests in each instance having been applied 72 hours before death. In these a cranotic area became evident, raised to an extent appreciable to light touch only.

(b) With the exception of the weakest positive exactions alreadr described, red was the characteristic colour. The degree of the reaction varied, and although always riolent in the most extensive reactions, there appeared to be no exact connection between the area corered by the final nodule and the intensity of the redness. 
(c) The diameter of the nodule varied from 10 to $25 \mathrm{~mm}$. In the most violent reactions where a peripheral erythema was present, the erythematous band measured from 3 to $38 \mathrm{~mm}$. giving corresponding orer-all diameters of 19 to $57 \mathrm{~mm}$.

No sloughing, systemic or focal reactions occurred in any of the positively reacting children, but of eleven adults tested, all of whom showed a positive reaction, three complained of a slight headache, and one, in addition, of transient nausea.

TABLE 1.

RESLLTS OF TCBERCCLIN TEST IN 612 CHILDREX IN AGE GROTPS.

\begin{tabular}{|c|c|c|c|c|c|}
\hline \multicolumn{3}{|c|}{ Age in years } & \multirow{2}{*}{ No. of tests } & \multirow{2}{*}{$\frac{\text { Positive reactions }}{15}$} & \multirow{2}{*}{$\frac{\text { Percentage }}{17 \cdot 7}$} \\
\hline Cnder $1 .$. & .. & .. & & & \\
\hline 1 and under & 3 & . & 13.5 & 36 & $26 \cdot 7$ \\
\hline $3,, \quad$, & 5 & . & 123 & 49 & $39 \cdot 8$ \\
\hline 5, & 7 & . & 104 & 43 & $41 \cdot 3$ \\
\hline $7,$, & 11 & . & 143 & 6.5 & $45 \cdot 6$ \\
\hline 11 up to 12 & .. & .. & 20 & 14 & $70-0$ \\
\hline Total & . & .. & 612 & 22-202 & \\
\hline
\end{tabular}

TABLE 2.

Nattre of 612 CaSes tested.

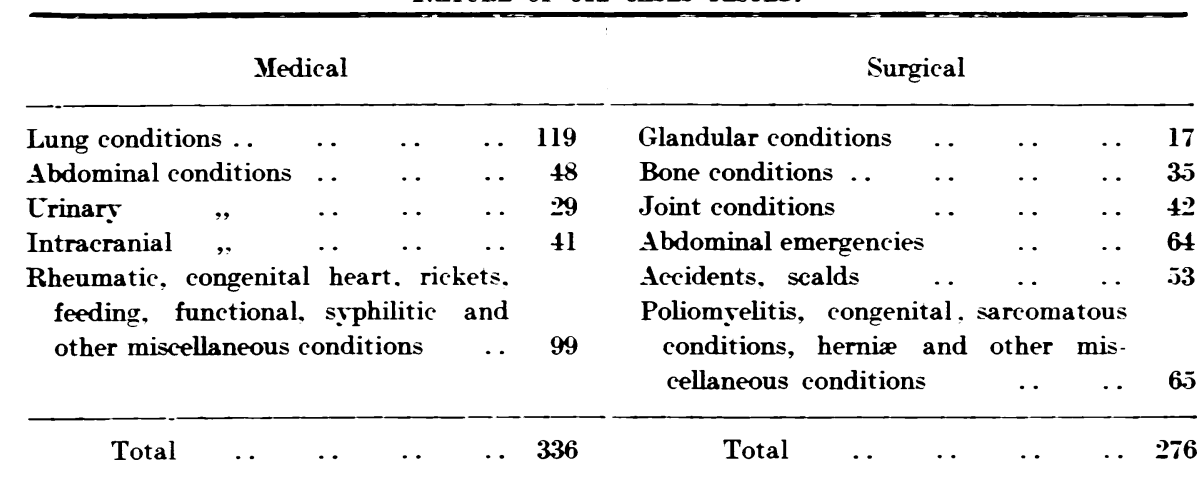

Times of reactions.-Except in the cases of outpatients all arms tested were examined daily for a period of ten days unless the case was previously discharged or died. No single case, other than several of those terminating fatally, was under observation for less than seren days. It was found that in a total of 222 positive results, a definite reaction was present in 196 within $\mathbf{2 4}$ hours, in $\mathbf{2 0}$ there was no reaction for $\mathbf{4 8}$ hours, in two for $\mathbf{7 2}$ hours, and only one was delayed for 96 hours before appearing.

Material investigated.-The tuberculin test, as outlined above, was carried out over a period of $3 \frac{1}{2}$ months on all children admitted to the Royal Edinburgh Sick Children's Hospital irrespective of the age of the child, or whether the case was medical or surgical in nature. Orer the entire series of 612 cases, all tests were carried out and read by one observer; Tables 1 and 2 illustrate the type of children embraced by the inrestigation. 
Results.

In an endeavour to assess the ralue of the method, investigations were carried out along the following lines :-

1. The reliability of the proposed method (i) as compared with the Pirquet and Mantoux tests ; (ii) as borne out by post-mortem findings ; and (iii) as seen in cases of clinical tuberculosis, in cases of massire tuberculosis, and in cases of high ferer.

2. The necessity or otherwise of using (a) a control solution; (b) bovine and/or human tuberculin.

3. The ease or otherwise of performance.

Comparison with the Pirquet test.-In 350 consecutive cases the method under trial was carried out on the left arm while the modified Pirquet test ${ }^{8}$ was performed on the other arm. Positive reactions occurred in both left and right arm in 125 cases. In one instance the Pirquet test gave only a dubious positive result while the multiple puncture method showed a definite reaction,and in another case there was no reaction in the latter method although the Pirquet test was positive. Repetition gave positive reactions to both tests in each instance.

Comparison with the Mantoux test.-In 50 instances the Mantoux test was carried out on cases previously subjected to the multiple puncture test and the results of the two methods tallied in all cases. Twelve positive reactions occurred in the series of 50 , and in the 38 cases showing no reaction either to the proposed method or the Mantoux test with a 1 in 1,000 dilution of old tuberculin, the Mantoux test was repeated using a 1 in 100 concentration without producing any hitherto unrerealed reactions.

Comparison with post-mortem findings.-Autopsies were carried out in 90 cases which had been subjected to the test during life and evidence of tuberculous infection was demonstrated in each of the $\mathbf{3 4}$ instances where a positive tuberculin reaction had been obtained. Included in these 34 cases were two in which no clinical evidence of tuberculosis had been found. One was a patient admitted on account of extensive burns, in whom were discovered calcified and caseous mediastinal glands with a fibrosis of the upper lobe of the right lung. The other was clinically a case of right lobar pneumonia in an infant of six months : autopsy confirmed this, but revealed also caritation in the left upper lobe and caseous thoracic glands.

In one single instance was tuberculous infection demonstrated in a case which had failed to react positively to the tuberculin test. This exception occurred in a boy suffering from acute streptococcal meningitis : in a moribund condition at the time of admission, he died without regaining consciousness 36 hours after performance of the test. Post mortem sereral mesenteric glands were found, judged to be tuberculous on their macroscopic appearance.

Results in clinical tuberculosis.-On their discharge the diagnoses of all cases under test were reviewed and the corresponding tuberculin reaction noted to assess the reliability of the method employed in cases of clinical tuberculosis. The term 'clinical tuberculosis' was taken to imply that the presence of Koch's bacillus had been proved, or that some pathological focus directly attributable to a tuberculous infection had been demonstrated. 
TABLE 3.

Cases of clistcal tTBerctlosis stbmitted to test.

\begin{tabular}{|c|c|c|c|c|c|c|c|c|c|c|c|}
\hline \multicolumn{6}{|c|}{ Medical } & \multicolumn{6}{|c|}{ Surgical } \\
\hline Meningitis & $\ldots$ & $\ldots$ & $\ldots$ & $\ldots$ & 22 & Cervical adenit & & . & 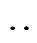 & . & 14 \\
\hline Pulmonary & .. & . & . & .. & 14 & Mesenteric ader & itis & .. & .. & .. & 2 \\
\hline Abdominal & .. & .. & .. & .. & 14 & Chronic osteom & elitis & .. & . & .. & 1 \\
\hline Generalized tube & ercul & & . & . & 4 & Chronic osteom & elitis & f spine & .. & .. & 3 \\
\hline Pleural effusion & .. & . & . & . & 8 & Arthritis .. & .. & .. & .. & .. & 9 \\
\hline Vrinary .. & . & . & . & . & 2 & Fæcal fistula & .. & .. & .. & . & 10 \\
\hline Total & .. & $\cdots$ & . & . & 64 & Total & . & $\cdots$ & . & .. & 39 \\
\hline
\end{tabular}

In the series of 612 children, 64 medical and 39 surgical were associated with a clinical diagnosis of tuberculosis, and Table 3 shows the relatire frequency of the various conditions.

A positive tuberculin reaction was obtained in all surgical and in 63 of the medical cases. The one exception occurred in a boy with tuberculous bronchopneumonia, remored from hospital 24 hours after the test had been carried out. At the time of removal a faint localized reddening was present over the test area, but there was no accompanying nodularity so that a positive result could not be claimed during the period of observation.

On the other hand, a number of cases were sent into hospital diagnosed as tuberculous, or subsequent to admission tentatively considered as such, but had the diagnosis revised before discharge. Such cases are shown in Table 4. In all of these the tuberculin test was carried out at least twice, with negative results each time.

Results in massive tuberculosis.-In Table 5 are tabulated the results of observations carried out on tuberculous cases which ended fatally, and on which post-mortem examinations were carried out.

Including the examples given in Table $\tilde{5}$, the test was applied to a total number of 22 cases of meningitis and 14 cases of pulmonary infection, clinically

TABLE 4.

RESTLT OF TEST IN DOLBTFLL CASES.

\begin{tabular}{|c|c|c|}
\hline Original diagnosis & Final diagnosis & Test \\
\hline Tuberculous abdomen. & Constipation. & Negative \\
\hline , & †Chronic volvulus & ," \\
\hline Tuberculous ischio-rectal abscess. & †Mixed infection, non-tuberculous & ,, \\
\hline Cerebellar tuberculoma (2). & $\dagger$ Megaloblastoma (2). & , \\
\hline Tuberculous meningitis & Polioencephalitis. & , \\
\hline .. & Encephalitis. & , \\
\hline , & *Diabetus mellitus. & , \\
\hline , $\quad$, & Apical pneumonia. & , \\
\hline Pulmonary tuberculosis (2). & *Broncho-pneumonia (2). & , \\
\hline Tuberculous glands (2). & $\begin{array}{l}\text { * Aleukæmic leukæmia. } \\
\text { †Appendicitis (2). }\end{array}$ & , \\
\hline
\end{tabular}


tuberculous. In each of these a positive reaction occurred, with the exception of the one boy already referred to in the previous section.

Repetition of the test and its value in cases of high fever.-In 100 cases which had shown no reaction, the test was repeated a second time on the 7th day, and in 30 cases a third time on the 12th day after the first application. Included in these 100 cases were 45 suffering from lobar pneumonia, and in them the test was performed within four hours of admission when the condition was at its height, while the second test was applied when the temperature had fallen to, and remained normal, for a minimum period of three dars.

In no case did repetition produce a positive result.

TABLE 5

RESTLTS OF TEST IN MASSIVE TL BERCLLOSIS.

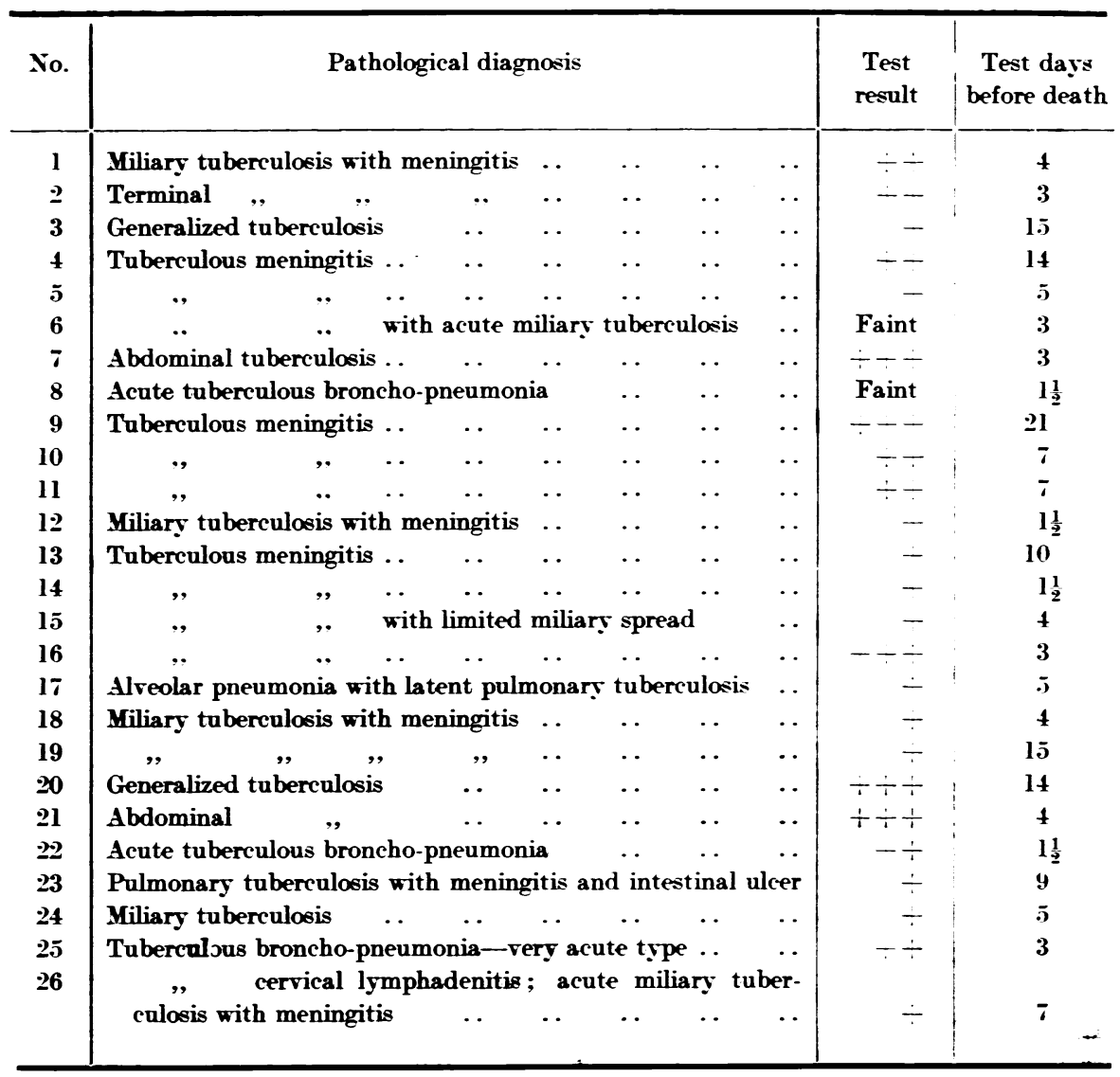

Control tests.-In a hundred consecutive cases, sterile glycerine with 5 per cent. phenol was used as control, and in only one instance was there a reaction in the control arm. In this the tuberculin reaction was violently positive, was $30 \mathrm{~mm}$. in diameter and was present for over six weeks, and the control reaction measured only $7 \mathrm{~mm}$. across, and appearing in 12 hours, disappeared in 36 hours. 
Taking the experience of other workers into account along with the above findings, it was not considered necessary to carry out control tests in further cases.

The use of human and or bovine tuberculin.-In a hundred cases no instance was met with in which a borine reaction was not accompanied by one to the human preparation while sereral cases reacted to the human and not the bovine tuberculin. These results were in keeping with those of other observers ${ }^{3}$, and in the rest of our series only the human tuberculin was used.

The ease of performance.-With a riew to estimating the reliability of the method in the hands of those inexperienced in its use, the resident and other members of the hospital staff as well as two risiting post-graduates were invited to co-operate. After having been once instructed in the technique, each of these individuals independently and unassisted, carried out the test on 10 to 20 children who had been previously tested by us. Among 100 unselected children not one of the $\mathbf{3 4}$ reacting positively to our test failed to show a similar result when tested by another party.

In one instance a reaction was obtained by a house-physician in a case of convalescent pericarditis which had failed to react when tested by us two months previously, at a time when the patient was at the most critical stage of his illness. A repeat test following on the result obtained by the housephysician showed a positive reaction.

\section{Discussion.}

References to the original tattoo method are limited to those by Wahl and Austenberger ${ }^{4}$ in 1923, and Forbes and Steinberg ${ }^{2}$ in 1930. The first two mentioned, in their joint paper, found the method intermediate in reliability between the Pirquet and Mantoux test. Forbes and Steinberg on the other hand, while preferring the Mantoux to the Pirquet method, published a series of results embracing 398 cases in which the positive results for tattoo and Mantoux tests tallied with the exception of one instance in which no reading positive or negative was noted for the tattoo test. Our results as shown abore suggest that the multiple puncture method loses nothing in reliability compared with either the Pirquet or Mantoux method.

Many inrestigators have reported failures of tuberculin tests in cases of massive tuberculosis.5, or in children wasted with long chronic disease ${ }^{6}$; failure is also said to occur where an acute illness associated with ferer is present. On the other hand, McNeil ${ }^{8}$ describes a modified method of performing the Pirquet test which in a limited number of cases he found not to fail even in massive tuberculous disease. As described above 350 children were subjected to the test using his technique and the results obtained in those cases which might be considered to be massive tuberculosis amply justified McNeil's claim. With regard to the multiple puncture method the results of our investigations suggest that it can lay claim to an equal reliability.

Using the multiple puncture test, no results were found to substantiate Smith's statement ${ }^{-}$that many children failing to react to a first test may do 
so a few days later. We do, howerer, agree with this same writer that in using either the Mantoux test or any form of Pirquet test it is not always easy to discriminate between a true mild reaction and that due to trauma. This difficulty does not arise using the instrument described at the outset : with it trauma is reduced to a minimum, and in cases showing no reaction the test area is difficult to locate.

Wahl and Gustenberger consider that, in comparison with the Burr or Pirquet method and the intracutaneous method, the tattoo technique requires greater skill, and that the need of accurately judging the depth of the needle prick militates against the chances of establishing a dependable test. In their application of the tattoo method these writers use a fine needle $\overline{0}-10$

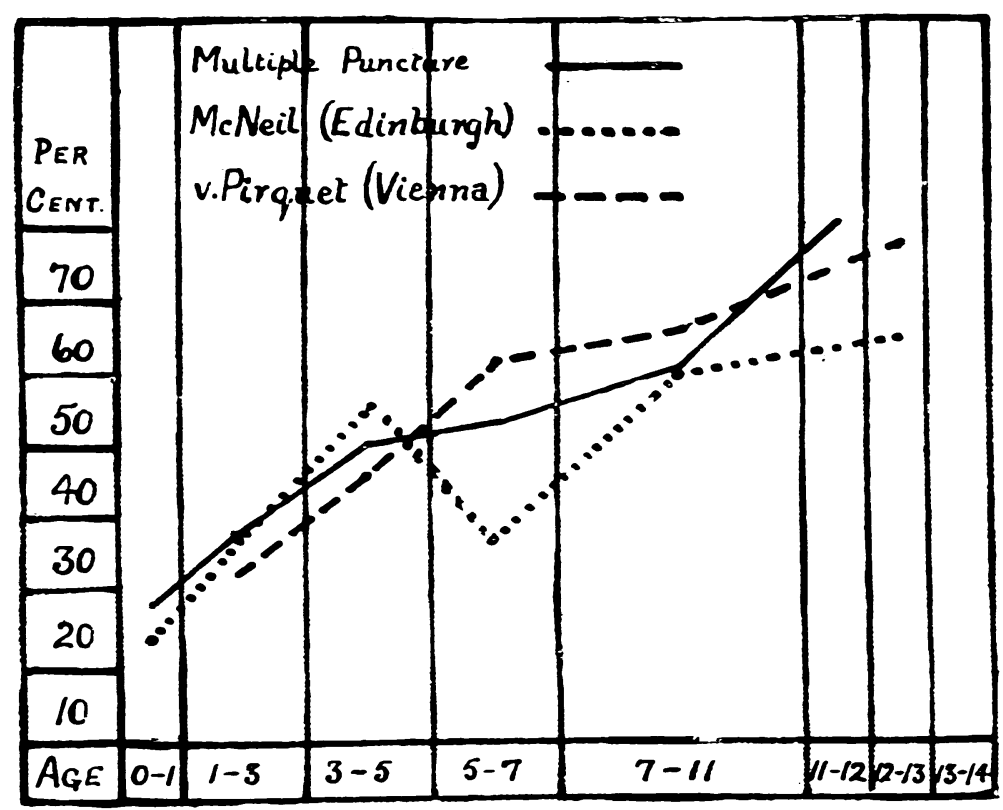

FIg. 3. Mlultiple puncture cutaneous tuberculin test. Percentage of positire reactions compared with results obtained by other cutaneous methods.

times in pricking through the tuberculin film, but by the use of the instrument described above, with its ease of control, it takes but little skill or practice to perform the test. Further, while experience allows of greater speed, eren in the hands of the inexperienced, a considerable saring of time is affected as compared with other tuberculin methods, and no loss in reliability is incurred.

In Fig. 3 the results obtained in the present series hare been plotted graphically against curves representing the findings of McNeil and Pirquet, and the close approximation of the graphs supports the contention that the tattoo method compares favourably with other methods. Our results (Table 3) show that the proposed technique is reliable in clinically manifest tuberculosis, and is also capable of revealing a latent infection (Fig. 4) where no clinical, bacteriological or radiological eridence has been demonstrated. 


\section{Conclusions.}

The multiple puncture method compares favourably with the Mantoux and Pirquet tests in all forms of tuberculosis in the matter of reliability.

It has distinct advantages over other methods in ease of procedure, speed of performance. absence of any but momentary slight discomfort. and absence of any tissue destruction eren in the most riolent reactions.

It is of particular value when used in children. especially for a routine method applicable to large numbers. The fact that it requires no particular skill in its performance makes the method especially suitable for use by anyone only occasionally carrying out a tuberculin test.

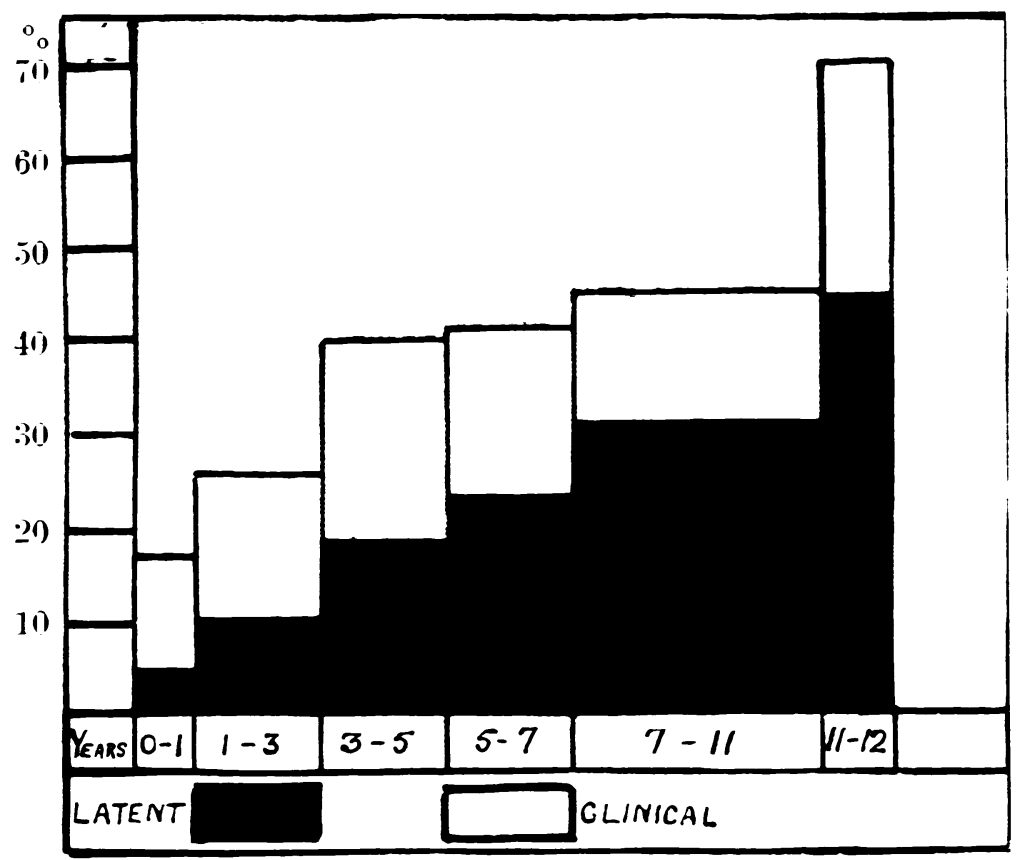

Fir. 4. Multiple puncture cutaneous tuberculin test : showing percentage of positive reactions at different age periods and relative incidence of latent and clinical cases.

My thanks are due to all physicians and surgeons of the Edinburgh Roval Hospital for Sick Children for granting access to their wards, and to other members of the hospital staff for their willing assistance.

\section{REFFRENCES.}

1. Craig. D. A.. J. Ali. Med. As.. ('hicago. 1916. LXVIII 122-

$\because$ Forbes, R. P. \& Steinberg. C. L.. Am. J. Dis. Child.. Chic., 1930. XL. 1230.

3. Uc.Neil. C., Edinburgh Yed. J.. Edin., 1912. X. S.. VIII. 324, 456.

4. Wahl, S. A. \& Gustenberger, H. J.. Arch. Ped.. X.Y.. 1923, XL, 143.

5. Dicker, L. B., Am. J. Dis. Child.. Chicago, 1929, XXXIIII, 115.5.

b. Dixon, A. B., Brit. M $\in$ d. J., Lond., 1931, i, 3668.

7. Smith, C. H., Am. J. Dis. Child., Chicago, 1929. XXXVIII. 1137.

๖. Mc.Neil. C., Brit. Med. J.. Lond.. 1923. i. 673. 